\title{
Extensive dissection of the pulmonary artery treated with combined heart-lung transplantation
}

\author{
W. A. Wuyts, MD, PhD, ${ }^{a}$ P. Herijgers, MD, PhD, ${ }^{b}$ W. Budts, MD, PhD, ${ }^{c}$ W. De Wever, $M D,{ }^{d}$ and M. Delcroix, MD, PhD, ${ }^{a}$ \\ Leuven, Belgium
}

丹 Supplemental material is available online.

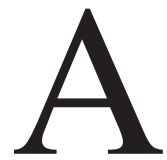

case of extensive dissection of the pulmonary artery was seen in a woman with pulmonary arterial hypertension $(\mathrm{PAH})$ with severe interscapular pain. The diagnosis was made on computed tomographic (CT) scan of the chest. This case report shows that in a patient with PAH with thoracic pain, dissection of the pulmonary artery needs to be excluded. The pathogenesis of pulmonary artery dissection is discussed, as well as diagnosis and therapeutic interventions.

\section{Clinical Summary}

A 48-year-old white woman had a history of PAH, diagnosed 20 years previously, associated with a ventricular septal defect. She had been treated with diuretics, but because of increased shortness of breath, the oral prostacyclin analog beraprost was initiated. This therapy was discontinued 11 months later, in August 2002, because of therapy-resistant gastritis. The endothelin receptor antagonist bosentan was started but discontinued after 1 year because of abnormal liver function tests. In October 2004, the patient was treated with sitaxsentan at $100 \mathrm{mg} / \mathrm{d}$ and did well for 2 months. Then she mentioned increased shortness of breath (New York Heart Association/World Health Organization functional class IIIV), associated with interscapular pain and intermittent fever episodes. On physical examination, there was an increased jugular venous pressure to $9 \mathrm{~cm} \mathrm{H}_{2} \mathrm{O}$ with positive hepatojugular reflux, respiratory rate of 36 breaths/min, prominent pedal edema, and ascites. In addition to sitaxsentan, the patient was receiving phenprocoumon at $1.5 \mathrm{mg} / \mathrm{d}$, bumetanide at $1 \mathrm{mg} / \mathrm{d}$, spironolactone at $50 \mathrm{mg} / \mathrm{d}$, digoxin at $0.125 \mathrm{mg} / \mathrm{d}$, and methimazole at $30 \mathrm{mg} / \mathrm{d}$. Full blood cell count, serum urea and electrolyte concentrations, liver function tests, thyroid function tests, and C-reactive protein level

From the Departments of Respiratory Medicine, Pulmonary Hypertension, ${ }^{a}$ Cardiac Surgery, ${ }^{\mathrm{b}}$ Cardiology, ${ }^{\mathrm{c}}$ and Radiology, ${ }^{\mathrm{d}}$ UZ Gasthuisberg, Leuven, Belgium.

Received for publication Jan 27, 2006; accepted for publication March 15, 2006.

Address for reprints: M. Delcroix, UZ Gasthuisberg, Department of Pneumology, Herestraat 49, B-3000 Leuven, Belgium (E-mail: marion.delcroix@ uz.kuleuven.be).

J Thorac Cardiovasc Surg 2006;132:205-6

$0022-5223 / \$ 32.00$

Copyright () 2006 by The American Association for Thoracic Surgery

doi:10.1016/j.jtcvs.2006.03.037 were all within normal ranges. Troponin was increased to 236 $\mu \mathrm{g} / \mathrm{L}$ (normal level $<0.13$ ). On room air, arterial blood gas values were as follows: $\mathrm{pH} 7.5, \mathrm{Po}_{2} 40 \mathrm{~mm} \mathrm{Hg}, \mathrm{PCO}_{2} 25 \mathrm{~mm} \mathrm{Hg}$, and oxygen saturation $81.4 \%$. Chest radiography showed bilateral hilar enlargement, dilatation of the pulmonary trunk, and a pleural effusion. A 12-lead electrocardiogram revealed sinus rhythm, incomplete right bundle branch block, and a right axis deviation. Echocardiography showed dilated right heart cavities and pulmonary artery systolic pressures of $70 \mathrm{~mm} \mathrm{Hg}$. A helical CT scan of the chest showed a complete dissection, starting from the pulmonary valve and progressing to subsegmentary branches of right middle and lower lobe artery (Figures 1 and E1). Because of the extensiveness of the dissection, it was decided to perform heartlung transplantation. Meanwhile, the patient was treated with cough suppressants, bronchodilation, and analgesics. The patient had several episodes of heavy interscapular pain, with an increase of troponin levels to a maximum of $39 \mu \mathrm{g} / \mathrm{L}$ and of serum lactate to $4.5 \mathrm{mmol} / \mathrm{L}(0.4-2.0 \mathrm{mmol} / \mathrm{L})$. The pleural effusion increased, and dobutamine was associated with good response. After 7 weeks on the urgent waiting list, the patient received a heart-lung transplantation (Figure 2) and completely recovered.

\section{Discussion}

A case of a extremely extensive pulmonary artery dissection associated with PAH is described here. It was successfully treated with combined heart-lung transplantation. As mentioned in a recent review of 63 cases of pulmonary artery dissection, ${ }^{1}$ only $13 \%$ of cases are diagnosed during life. Usually the dissection leads to a rupture, resulting in pericardial tamponade or major bleeding and subsequent death. ${ }^{2}$ Symptoms are nonspecific, such as chest pain, dyspnea, and cyanosis. ${ }^{2}$ Chest radiography may show pleural effusion, mediastinal widening, and hilar masses. ${ }^{3}$ Echocardiography is a noninvasive method that is sometimes useful to visualize a dissection. CT scan and magnetic resonance imaging of the chest are both able to detect an intimal flap and a false lumen. ${ }^{3}$

Reported underlying conditions are cardiac disease $(n=34 / 63$, mainly patent ductus arteriosus and rheumatic mitral valve stenosis), idiopathic PAH $(n=9)$, pulmonary artery thrombosis $(n=4)$, chronic obstructive pulmonary disease $(n=4)$, catheter-induced dissection $(n=2)$, and unknown $(n=10)$. It is thought that medial degeneration, dilatation of the vessel, increased shear stress, and increased pressure in the vessel may result in an intimal tear. Some of the current PAH treatments are known to inhibit smooth muscle cell proliferation and synthesis of collagen by fibroblasts and thus may even be involved in the pathogenesis of sudden pulmonary artery dissection.

In patients with $\mathrm{PAH}$, differential diagnosis with more usual causes of chest pain, such as left coronary artery compression by 


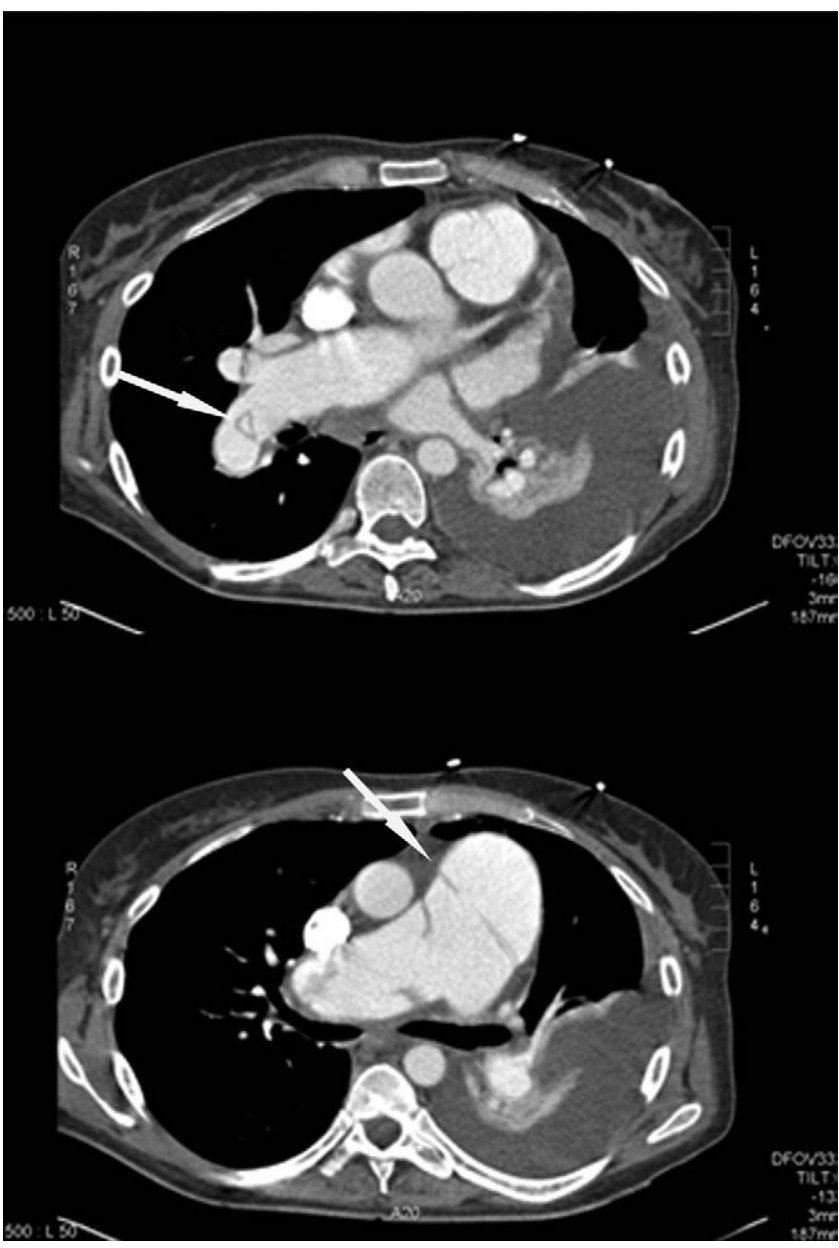

Figure 1. Helical CT scan of chest shows line (arrows) consistent with dissection of pulmonary artery, starting from pulmonary valve and continuing to subsegmentary branches of right middle and lower lobe artery.

a dilated pulmonary artery trunk or right ventricular ischemia as a result of decreased coronary driving pressure, must be considered. Stenting, bypassing, ${ }^{4}$ and atrial septostomy are the appropriate therapies for these entities.

Some authors suggest urgent corrective surgery to prevent rupture and possible death. ${ }^{2,3}$ To the best of our knowledge, surgery has been described only for limited dissection. In this case, combined heart-lung-transplantation was performed. There is only one previous report of a patient successfully treated for this entity with combined heart-lung transplantation. ${ }^{5}$

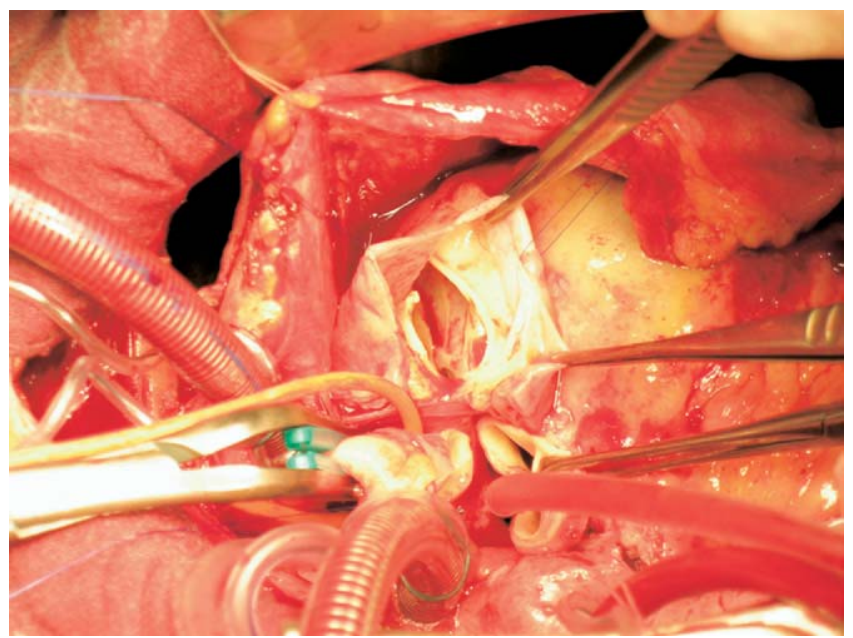

Figure 2. Picture obtained during heart-lung transplantation clearly shows intimal tear in pulmonary artery. Surgery revealed complete dissection, starting from pulmonary valve and progressing to subsegmentary branches of right middle and lower lobe artery, as seen on imaging.

\section{Conclusion}

We describe here the insidious onset of a pulmonary artery dissection in a hemodynamically stable patient with PAH. The clinician must be aware of the possibility of pulmonary artery dissection in patients with chest pain and underlying PAH. Moreover, with improving diagnostic and surgical capabilities, it is possible to make a diagnosis before rupture occurs, turning this usually lethal disorder into a potentially treatable disorder.

\section{References}

1. Khattar RS, Fox DJ, Alty JE, Arora A. Pulmonary artery dissection: an emerging cardiovascular complication in surviving patients with chronic pulmonary hypertension. Heart. 2005;91:142-5.

2. Senbaklavaci O, Kaneko Y, Bartunek A, Brunner C, Kurkciyan E, Wunderbaldinger $\mathrm{P}$, et al. Rupture and dissection in pulmonary artery aneurysms: incidence, cause, and treatment-review and case report. J Thorac Cardiovasc Surg. 2001;121:1006-8.

3. Wunderbaldinger P, Bernhard C, Uffmann M, Kurkciyan I, Senbaklavaci $\mathrm{O}$, Herold CJ. Acute pulmonary trunk dissection in a patient with primary pulmonary hypertension. J Comput Assist Tomogr. 2000;24: 92-5.

4. Decuypere V, Delcroix M, Budts W. Left main coronary artery and right pulmonary vein compression by a large pulmonary artery aneurysm. Heart. 2004;90:e21.

5. Tonder N, Kober L, Hassager C. Pulmonary artery dissection in a patient with Eisenmenger syndrome treated with heart and lung transplantation. Eur J Echocardiogr. 2004;5:228-30. 


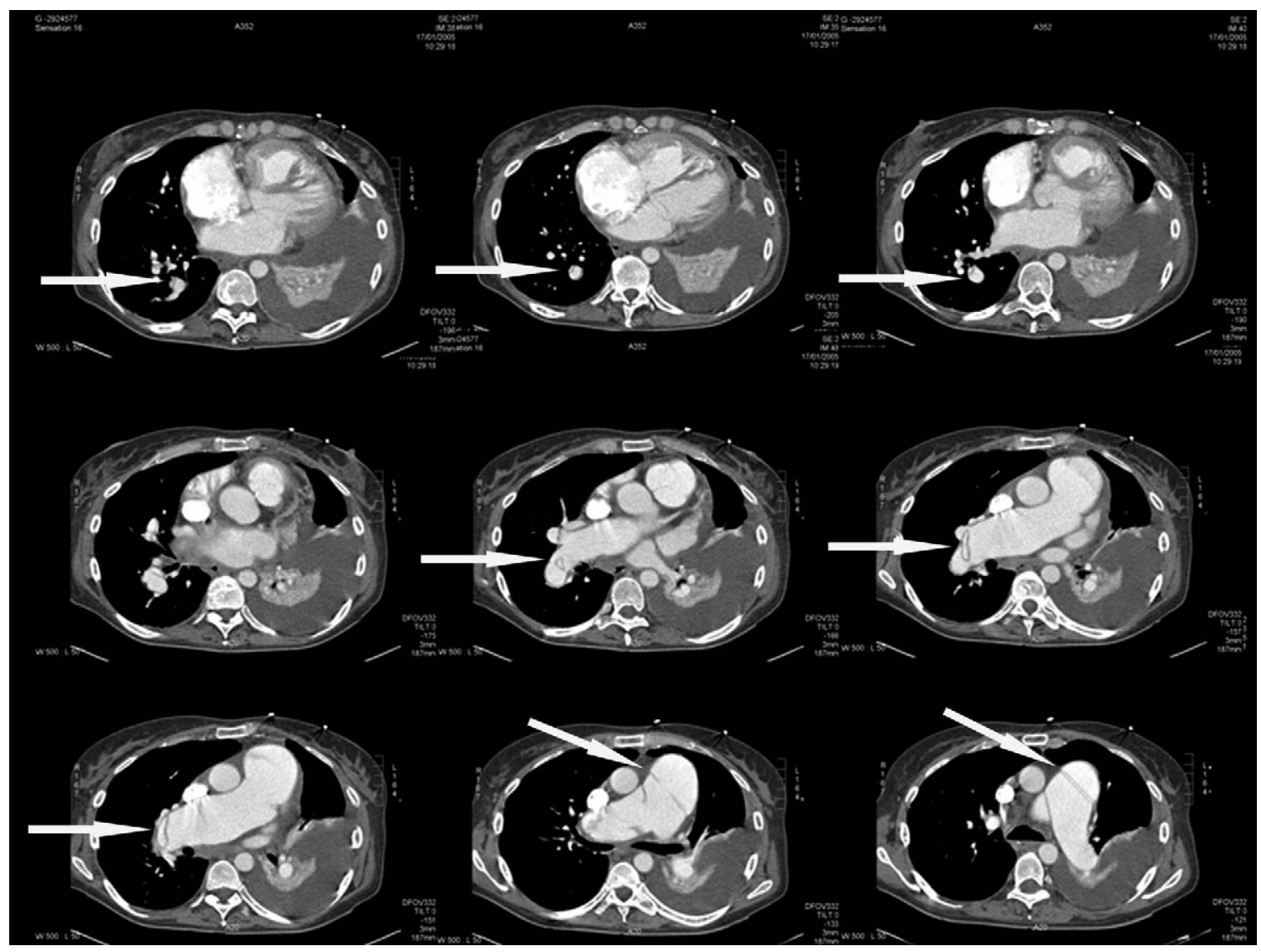

Figure E1. Helical CT scan of chest (more extensive version of Figure 1) shows line (arrows) consistent with dissection of pulmonary artery, starting from pulmonary valve and continuing to subsegmentary branches of right middle and lower lobe artery. 